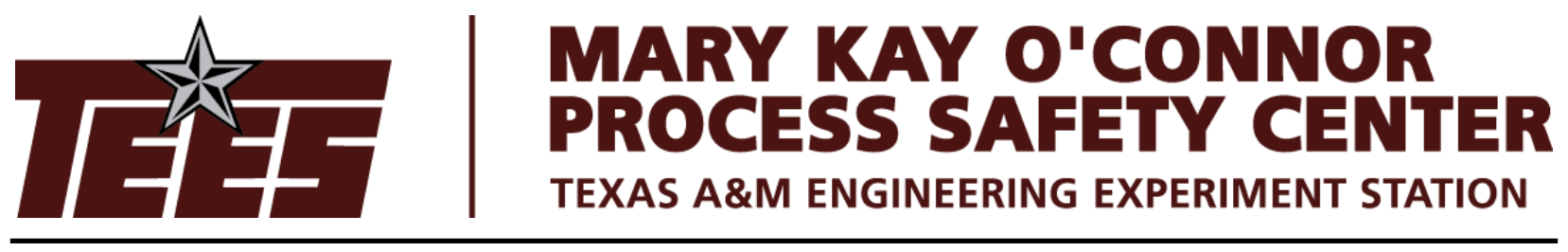

$22^{\text {nd }}$ Annual International Symposium

October 22-24, 2019 | College Station, Texas

\title{
Biocompatible Herder for Rapid Oil Spill Treatment over a Wide Temperature Range
}

Mingfeng Chen ${ }^{\mathrm{c}}$, Zhengdong Cheng ${ }^{\mathrm{a}, \mathrm{b}, \mathrm{c}, *}$, Dali Huang ${ }^{\mathrm{a}, \mathrm{b},+}$, Shijun Lei ${ }^{\mathrm{c}}$, Rong $\mathrm{Ma}^{\mathrm{c}}$, M. Sam

Mannan $^{\mathrm{b}, \mathrm{c}}$, Roshan Sebastian $^{\mathrm{b},+}$, Abhijeet Shinde ${ }^{\mathrm{c}}$, Hongfei Xu ${ }^{\mathrm{b}, \mathrm{c}}$, Lecheng Zhang ${ }^{\mathrm{c}}$

${ }^{a}$ Department of Materials Science \& Engineering, Texas A\&M University, College Station, TX, 77843-3122, USA

b Mary Kay O'Connor Process Safety Center, Artie McFerrin Department of Chemical

Engineering, Texas A\&M University, College Station, TX, 77843-3122, USA

${ }^{\mathrm{c}}$ Artie McFerrin Department of Chemical Engineering, Texas A\&M University, College Station, TX, 77843-3122, USA

*Presenter's E-mail: zcheng@tamu.edu

\begin{abstract}
Oil spills caused by damaged oil rigs, ruptured pipelines, and tankers can have immediate and long-term detrimental effects on marine systems and aquatic life. Herein we further develop the merit of an oil spill recovery technique called oil herding. A herder is an amphiphilic oil-collecting surfactant which is applied to spray around the oil spill areas and is able to retract oil slicks, transforming them from a large thin layer to a small thick bulk. This herding treatment greatly simplifies further in-situ burning and the recycle process. The natural konjac glucomannan (KGM) material could be functionalized and examined here as an oil herder, which has the great advantage of nontoxicity, biocompatibility, and adaptability. Moreover, functionalized KGM is a non-ionic surfactant with no Krafft temperature. The absence of Krafft temperature gives KGM surfactants the unique ability to retain surfactant ability at temperatures nearing $0{ }^{\circ} \mathrm{C}$. It unlocks a new direction for efficient oil herders within low temperature water areas, especially for oil spills treatment in Arctic waters, in the offshore safety control.
\end{abstract}

Keywords: Herders, Biocompatible, Oil spill response, Wide temperature range, Functionalized konjac glucomannan, Oil contamination treatment

\section{Introduction}

Oil spills are environmental catastrophe; oil kills sea flora and fauna, contaminates fragile ecosystems, sea creature nursery areas, and soil beaches, among other destruction (Paine et al., 1996; Peterson et al., 2003). Occurring either accidently or deliberately, oil spills can result from malfunctions at offshore drilling rigs, from pipeline and holding tank ruptures at ports, and well blowout (Iakovou et al., 1997). On the other side, the petroleum products play a pivotal role to 
help human beings maintain a decent standard of living. The increase in demand for petroleum products engenders an uptick in petroleum exploration, production, and transportation (Brown et al., 1987; Urquhart, 1986). Oil is stored and processed along different nodes at terminals and refineries. Accordingly, an oil spill can take place at any point in these transportation modes, storage or processing locations. Fig. 1 labelled the 15 largest oil spills in history occurrence in the world up to 2019 (Baffes, 2007; Kaushik, 2019). Oil spills could occur on any continent and in any ocean, in extreme temperature ranges, from Arctic to Equatorial. Table 1 summarizes the 15 largest oil spills in history corresponding to Fig. 1. It is worth noting that large-scale oil spills as shown in Fig. 1 and summarized in Table 1 resulted in huge socio-economic impacts and attracted negative media and public attention. Besides of larger oil spills, more than half of the oil spills incidents are smaller in magnitude and are commonly existing, which often evade attention and more difficult to clean up (Blumer et al., 1971; Jesus, 2016). Additionally, The National Science Foundation (NSF) has lately developed a "NSF's 10 Big Ideas" plan, which one of the ideas is named as "Navigating the New Arctic". Energy crisis is not a new topic nowadays while there are around $1 / 3$ of the world's undiscovered gas and $1.68^{*} 10^{13}$ gallons of oil in the Arctic area. The energy concerns would be significantly lessened and the reliance on other types of energy would also be reduced. Many countries and oil companies have oil platforms in the Arctic, but the oil drilling also comes out with the oil spill problem. The extreme climate (low temperature of -2 to $2{ }^{\circ} \mathrm{C}$ in Fig. 1) and Arctic geographic location also play an important role to the spill effect and made the oil spill treatment situation more complicate.

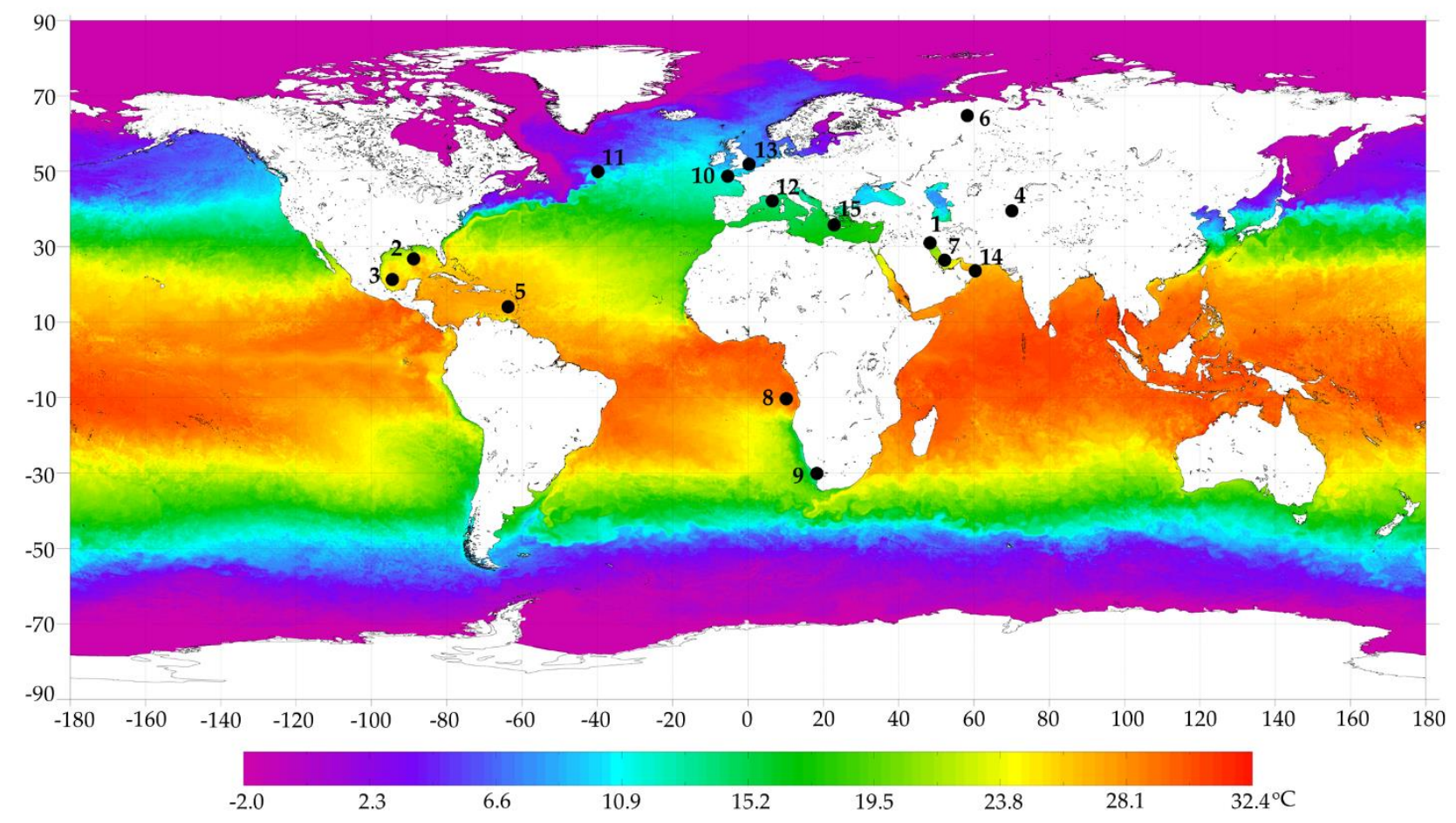

Fig. 1. The world map showing locations of the 15 largest oil spills in history and sea surface temperature (5 kilometers) contour chart. The black dots designate location of oil spills and numbers from 1 to 15 mean the volume ranking of the oil spill. 
Table 1 List of 15 largest oil spills in history (corresponding to Fig. 1)

\begin{tabular}{|c|c|c|c|c|c|}
\hline Ranking & Date & Cause & Location & Source & $\begin{array}{l}\text { Oil spill } \\
\text { volume } \\
\text { (million } \\
\text { gallons) }\end{array}$ \\
\hline 1 & 1991.01 .23 & Gulf War & Persian Gulf & Oil rig & 400 \\
\hline 2 & 2010.04 .20 & $\begin{array}{c}\text { Rig } \\
\text { explosion }\end{array}$ & Gulf of Mexico & $\begin{array}{c}\text { Deepwater } \\
\text { Horizon } \\
\text { oil rig }\end{array}$ & 210 \\
\hline 3 & 1979.06.03 & Well blowout & Gulf of Mexico & Ixtoc 1 Oil Well & 140 \\
\hline 4 & 1992.03 .02 & Well blowout & $\begin{array}{l}\text { Fergana Valley, } \\
\text { Uzbekistan }\end{array}$ & Oil well & 88 \\
\hline 5 & 1979.07.19 & $\begin{array}{l}\text { Tanker } \\
\text { collision }\end{array}$ & $\begin{array}{l}\text { Trinidad \& } \\
\text { Tobago }\end{array}$ & $\begin{array}{c}\text { Atlantic } \\
\text { Empress/ } \\
\text { Aegean Captain } \\
\text { Oil Tanker }\end{array}$ & 87 \\
\hline 6 & 1994.09.08 & Dam burst & $\begin{array}{c}\text { Kharyaga, } \\
\text { Russia }\end{array}$ & Oil reservoir & 84 \\
\hline 7 & 1983.02 .04 & Collision & $\begin{array}{l}\text { Persian Gulf, } \\
\text { Iran }\end{array}$ & $\begin{array}{l}\text { Nowruz Fields } \\
\text { Platform }\end{array}$ & 80 \\
\hline 8 & 1991.05 .28 & Explosion & Angola Offshore & ABT oil tanker & 79 \\
\hline 9 & 1983.08.06 & $\begin{array}{l}\text { Fire on } \\
\text { tanker }\end{array}$ & $\begin{array}{l}\text { Cape Town, } \\
\text { South Africa }\end{array}$ & $\begin{array}{l}\text { Castillo de } \\
\text { Bellver } \\
\text { oil tanker }\end{array}$ & 78 \\
\hline 10 & 1978.03.16 & $\begin{array}{l}\text { Tanker } \\
\text { sinking }\end{array}$ & $\begin{array}{c}\text { Coast of } \\
\text { Brittany, France }\end{array}$ & $\begin{array}{c}\text { Amoco Cadiz } \\
\text { oil tanker }\end{array}$ & 69 \\
\hline 11 & 1988.11 .10 & $\begin{array}{l}\text { Tanker } \\
\text { explosion }\end{array}$ & $\begin{array}{l}\text { North Atlantic } \\
\text { off Coast of } \\
\text { Canada }\end{array}$ & $\begin{array}{l}\text { Odyssey } \\
\text { oil tanker }\end{array}$ & 43 \\
\hline 12 & 1991.04 .11 & $\begin{array}{c}\text { Tanker } \\
\text { explosion }\end{array}$ & $\begin{array}{l}\text { Coast of Genoa, } \\
\text { Italy }\end{array}$ & $\begin{array}{l}\text { MT Haven } \\
\text { oil tanker }\end{array}$ & 42 \\
\hline
\end{tabular}




$\begin{array}{cccccc}13 & 1967.03 .18 & \begin{array}{c}\text { Tanker } \\ \text { leakage }\end{array} & \begin{array}{c}\text { Southwest Coast } \\ \text { of United } \\ \text { Kingdom }\end{array} & \begin{array}{c}\text { Torrey Canyon } \\ \text { oil tanker }\end{array} & 36 \\ 14 & 1972.12 .19 & \begin{array}{c}\text { Tanker } \\ \text { collision }\end{array} & \text { Gulf of Oman } & \begin{array}{c}\text { Sea Star oil } \\ \text { tanker }\end{array} & 35 \\ 15 & 1980.02 .23 & \text { Tanker fire } & \text { Port of Pylos } & \begin{array}{c}\text { Irenes Serenade } \\ \text { oil tanker }\end{array} & 30\end{array}$

Oil spills in ocean circumstances have resulted in irreversible negative environmental impacts and pecuniary loss (Goldberg, 1994; Silliman et al., 2012). Oil slick would float on the water and spread because of the smaller specific gravity and surface free energy. The spilled oil has capability to affect the delicately poised marine ecosystem and can trigger a domino effect which can have deleterious effects on the coastal belt and human lives. Hence, it is imperative to have in place an effective and rapid oil spill response system.

Oil spill treatment methods have many different classifications and circumscriptions. Here, the commonly used category for oil spill remediation in the aquatic environment includes mechanical, chemical, and biological procedures. The mechanical methods using oil booms, skimmers, barriers or sorbents are the most universal method for dealing with oil spill. Engineers use machines and instruments to physically suck up oil or absorb oil from water surface which needs large manual labor forces and resources. Also, the mechanic recovery would be largely affected by offshore changeable environment. In the chemical treatment, dispersants could be used to break large oil area into small size oil droplets. It would bond with oil and water and it is inevitable that the dispersants have biocompatibility and toxicity problem, which would greatly affect marine system in the oil spill location. Bacteria and microorganisms could eat or break toxic oil components into non-toxic matters. But it is slow in time and not suitable in very low temperature areas or close to coastal. In oil spill accidents discussed in Fig. 1 and Table 1, one method or composite methods were used to handle with oil spill. Regardless of the physical oil booms, barriers and in situ burning, the commonly used oil spill treatment methods for the accidents above was to spray dispersant like Corexit 9500A, Corexit 9527A, JD-2000 or MARE CLEAN 200, which mostly have been reported to have known or unpredictable effect to the marine system.

In this work, we explore an effective chemical herding method. The herders, or called herding surfactants, reduce air-water surface tension and retract the thin spilled oil to form a thick slick layer, which will then favor in-situ burning and recovery. Herder is a surfactant whose chemical structure includes the hydrophobic tail and the hydrophilic head. It is comparatively effective in remote offshore waters, while other mechanical, biological and chemical methods are not that convenient nor efficient to some extent (Aggarwal et al., 2017).

Traditional oil herders have two major shortcomings. One is the toxicity impact and stubborn bio-incompatibility which will make the herding surfactant remain on water body for a long period (Imai et al., 1994; Inácio et al., 2013). The other is that the traditional herders would lose most herding efficiency in Arctic areas due to their intolerance to low temperatures. They 
suffer from a relatively high Krafft temperature, below which surfactants lose their surfactant property. The definition of Krafft temperature is the minimum temperature for surfactant to form micelles. There is an abrupt large solubility increase above the Krafft temperature (Bakshi and Singh, 2005; Rico and Lattes, 1986).

Our project focused on developing an innovative oil herder from natural plant-based product, konjac. The konjac glucomannan (KGM) is the base material used to develop the proposed oil herder, which is a natural polysaccharide and has flexibility in functionalization (Behera and Ray, 2016; Nishinari, 2000). The easily degraded functionalized KGM materials have both hydrophobic tails to be attached and hydrophilic backbones forming the surfactant structure. The natural KGM material could be functionalized to work as the efficient oil herder. Compared with traditional ionic surfactant, the non-ionic functionalized KGM surfactant does not have Krafft temperature limits and its herding efficiency is not restricted at low temperatures around $0{ }^{\circ} \mathrm{C}$. Results of this study demonstrated that functionalized KGM has great potential to work as an efficient biocompatible oil herder for a wide range of temperatures, especially suitable for oil spills response in Arctic Circle.

\section{Results and Discussion}

The schematic mechanism of oil herding was shown in Fig. 2. When inevitable accidents occur at sea, crude oil leaks out, spreading across the water surface and stabilizing as a very thin layer. After the herder (float on water and surround oil) was spread around the oil, the bulk oil slick started to shrink and become thicker (Fig. 2(a)). In the side view of oil herding theory, as shown in Fig. 2(b), initially had the tendency to spread out to become a very thin oil slick surface due to the gravitational force and smaller surface tension. Before herding surfactant was applied, oil on water surface system experienced with three forces, the oil-water surface tension $\left(\gamma_{\mathrm{O} / \mathrm{w}}\right)$, the oil-air surface tension $\left(\gamma_{\mathrm{O} / \mathrm{A}}\right)$ and the air-water surface tension $\left(\gamma_{\mathrm{A} / \mathrm{W}}\right)$. Water is a highly polar solvent and has high surface tension $\left(\gamma_{\mathrm{A} / \mathrm{W}}=72.5 \mathrm{mN} / \mathrm{m}\right)$ (Vargaftik et al., 1983). The $\gamma_{\mathrm{O} / \mathrm{W}}$ and $\gamma_{\mathrm{O} / \mathrm{A}}$ majorly depend on oil and water properties and the net sum value $\left(\gamma_{\mathrm{O} / \mathrm{w}}+\gamma_{\mathrm{O} / \mathrm{A}}\right)$ is around $25 \mathrm{mN} / \mathrm{m}$ (Gupta et al., 2015; Venkataraman et al., 2013). Higher $\gamma_{\mathrm{A} / \mathrm{w}}$ made the oil slick quickly spread outside from center until $\gamma_{\mathrm{A} / \mathrm{W}}$ and $\left(\gamma_{\mathrm{O} / \mathrm{W}}+\gamma_{\mathrm{O} / \mathrm{A}}\right)$ value are the same. At this moment, the oil slick became a very thin layer and reached the equilibrium state. The herder structure in Fig. 2(b) consists of a hydrophobic tail (black line) and hydrophilic head (red dot). After the herder was applied to the sea, the equilibrium state of $\gamma_{\mathrm{A} / \mathrm{W}}$ and $\left(\gamma_{\mathrm{O} / \mathrm{W}}+\gamma_{\mathrm{O} / \mathrm{A}}\right)$ was broken. The hydrophilic head dissolved on the water surface and to form a monolayer, and the hydrophobic tail forms an interface between the air and the water, which in effect greatly reduced the air-water surface tension $\left(\gamma_{\mathrm{A} / \mathrm{W}}<25 \mathrm{mN} / \mathrm{m}\right)$. Higher $\gamma_{\mathrm{O} / \mathrm{W}}+\gamma_{\mathrm{O} / \mathrm{A}}$ value motivated oil slick to contract until all surface tensions reach to the new equilibrium. At this moment the oil slick became a much thicker bulk. The oil slick on water was always moving to the direction of the equilibrium state and surface tensions are also adjusting at the same time. 
(a)
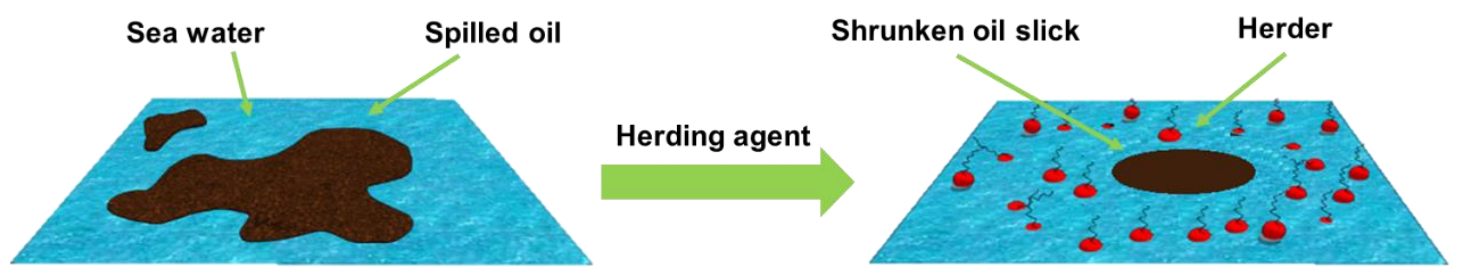

(b)

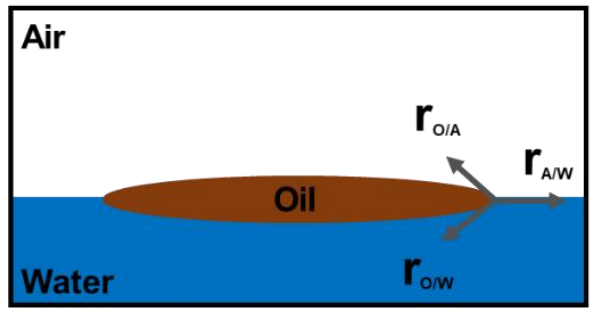

Before Herding Interaction

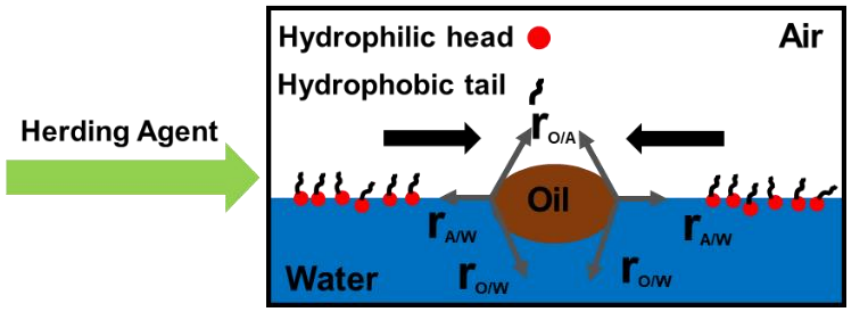

After Herding Interaction

Fig. 2. Schematic illustration for oil herding on the sea surface. (a) General $45^{\circ}$ view of herding process before and after addition of the herding agent. (b) Side view of herding mechanism before and after adding herding agent. The hydrophilic head and hydrophobic tail of the surfactant are labeled.

The lab-scale oil herding process experiment was first tested using the configuration shown in Fig. 3. The crystallizing dish simulated the sea environment. Artificial sea water was prepared using ASTM International standard protocol (ASTM D1141-98) with deionized (DI) water and dissolved mineral salts. The oil spill was replaced with dodecane $\left(\mathrm{C}_{12} \mathrm{H}_{26}\right)$ due to its liquid alkane hydrocarbon characteristic. The water was dyed with water-soluble methylene blue; the oil dodecane was dyed with oil-soluble Sudan IV for easier observation. A portable camera was clamped to a supporting mast and positioned above the crystallizing dish to record changes of the oil slick.

(a)

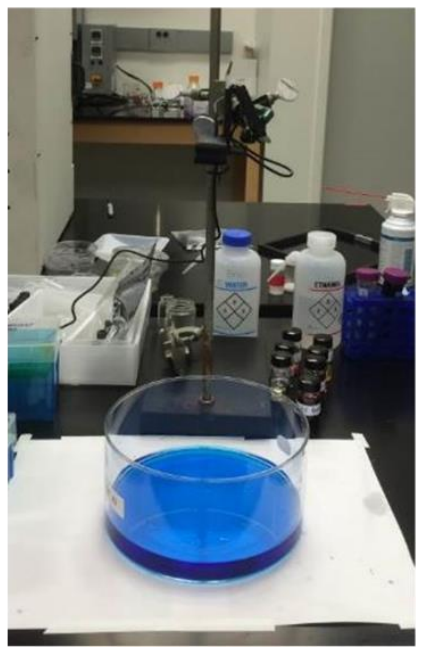

(b)

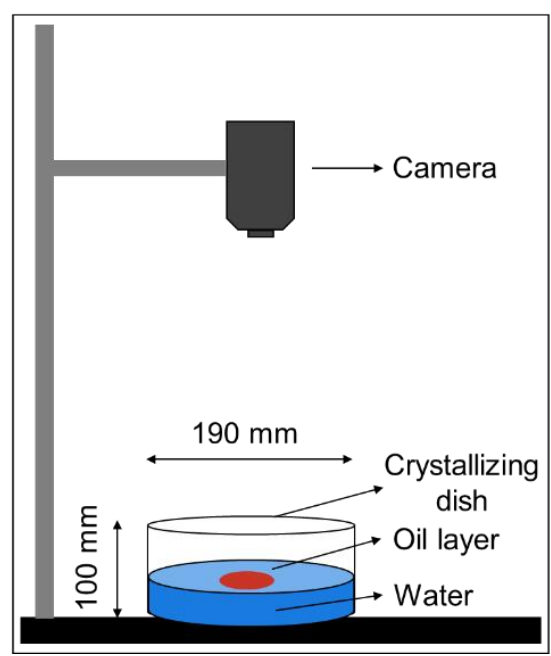

Fig. 3. Experimental setup for oil herding process. (a) Photograph of experimental setup in lab. (b) Schematic illustration of experiment design and instrument. 
Herding surfactant is essentially a surface-active agent. To preliminarily investigate the material herding efficiency to oil, suitable polymer surfactants with hydrophobic head and hydrophilic tail (similar to Fig. 2(b) surfactant structure) were tested. Polyethylene glycol (PEG) is a water soluble polymer and easy to couple with hydrophobic chain to form surfactant (Komoto and Kobayashi, 2004; Winger et al., 2009). Four common lab PEG derivatives were chosen as herders for testing, as shown in Fig. 4. The experiments were performed at room temperature. The slick thickness ratio was defined as below.

Slick thickness ratio $(\%)=\frac{\text { Stable Oil thickness before herding }}{\text { Stable Oil thickness after herding }}$

Higher slick thickness ratio implied better herding quality. From Fig. 4(a) and Fig. 4(b), the slick thickness ratio largely increased with herder concentration increment while the oil slick, accordingly, shrunk. The same changes could be also seen from the two insets, which demonstrated that PEG-monolaurate and PEG-monooleate surfactants were efficient in herding. While for Fig. 4(c) and Fig. 4(d), the slick thickness ratio remained mostly the same when herder concentration increased, demonstrating that PEG-dibenzoate and PEG-disterate were not suitable for herding oil. The effectiveness of surfactants at herding oil is directly related to the chemical structure of the PEG derivatives. Fig. 4(a) and Fig. 4(b) showed good herding ability due to their amphiphilic characteristics. The reason of slick thickness ratio curve of Fig. 4(c) and Fig. 4(d) remained flat were assumed to be its internal chemical structure large benzene rings and two side longer carbon chains. The benzene rings and longer carbon chains affected the steric hindrance of materials and largely restricted the hydrophobic side reaction with oil slick. They could not perform herding effect and thus curves in Fig.4c and 4d remained flat, and the thickness ratio was close to 1. 
(a)

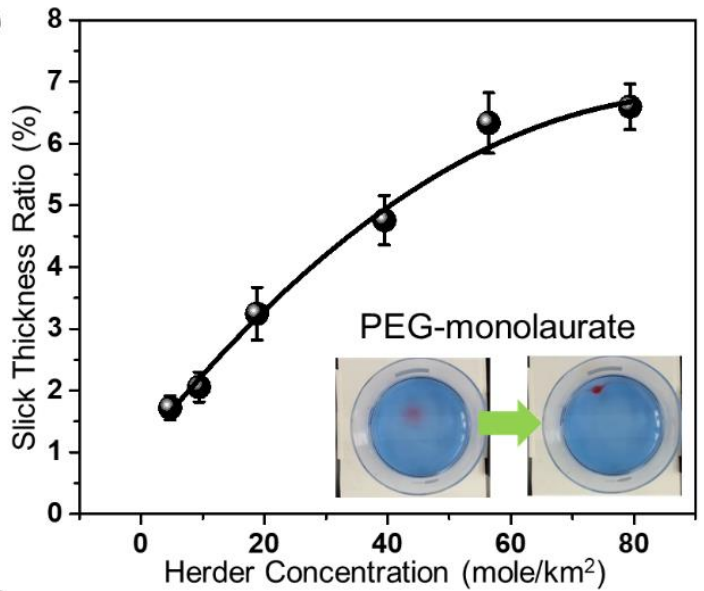

(c)

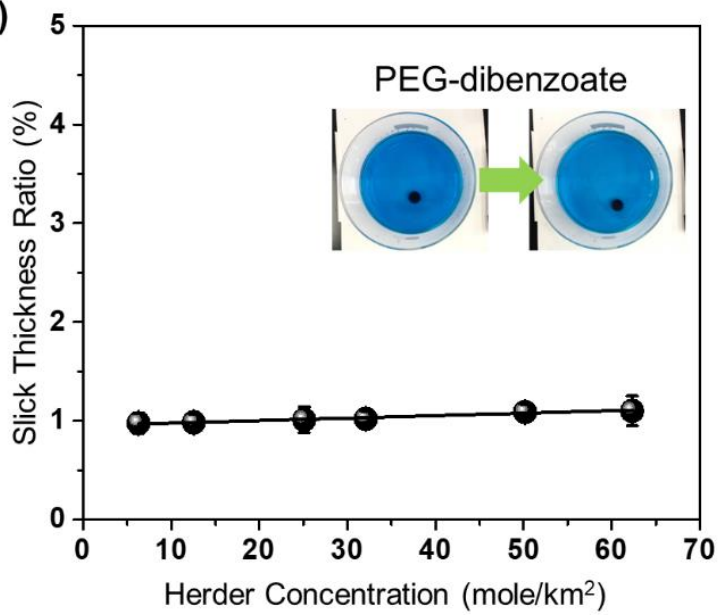

(b)

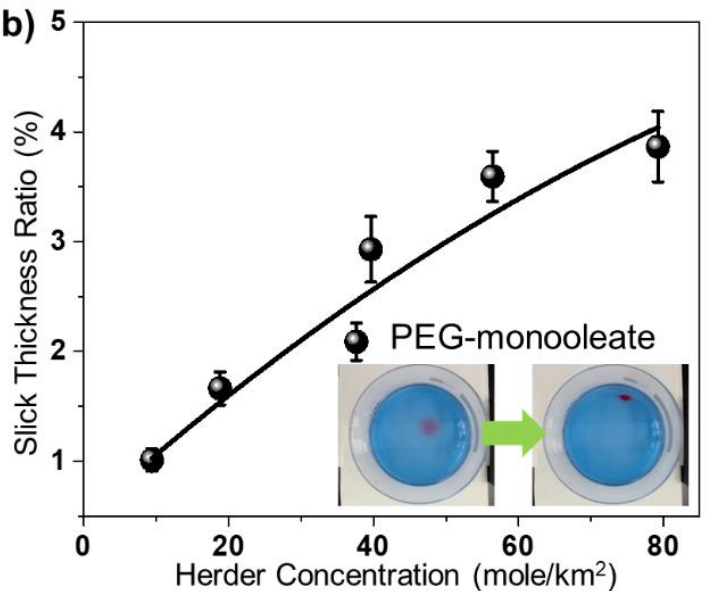

(d)

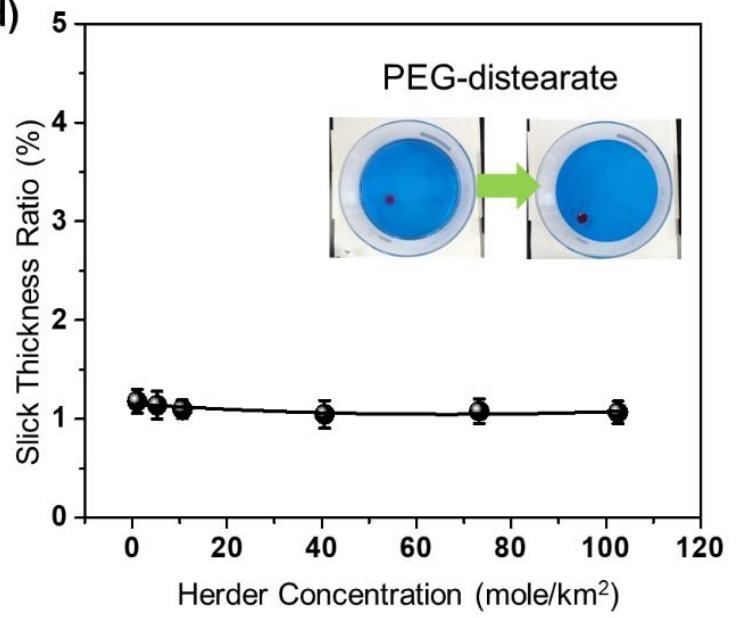

Fig. 4. Lab conventional herding surfactant efficiency evaluation at room temperature. Oil slick thickness ratio changes with the herder surfactant concentration of (a) PEG-monolaurate, (b) PEGmonooleate, (c) PEG-dibenzoate, (d) PEG-distearate. The insets are the photographs of equilibrium state before and after adding herders.

More comparisons were tested to study herder efficiency with different commercial surfactants at varying temperatures and salinity. From Fig. 5(a), both surfactants, Span-20 and PEG-monolaurate, presented good herding ability with large slick thickness ratios at $25^{\circ} \mathrm{C}$. In Fig. 5(b), the PEG-monolaurate retained high herding ability under $25{ }^{\circ} \mathrm{C}$. While temperature decreased to $4{ }^{\circ} \mathrm{C}$, which is close to Arctic Ocean temperature, oil slickness ratio maintained around 1.0, regardless of the herder concentration increment. The results demonstrated that PEGmonolaurate was not a good herder for oil spill response in low-temperature areas. Then herding efficiency of PEG-monolaurate surfactant in saline water and pure DI water was tested. As shown in Fig. 5(c), there was no clear oil slick thickness ratio change between PEG-monolaurate in pure water and $3.5 \%$ saline water, meaning the surfactant was not significantly affected by salinity. All the results above urged us to design and synthesize one new herding surfactant to replace PEGmonolaurate for overcoming the low temperature herding defect. 
(a)

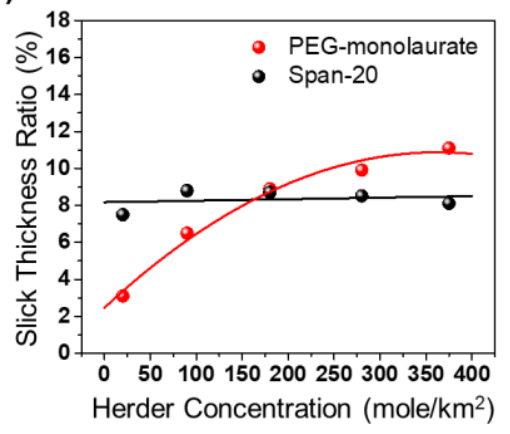

(b)

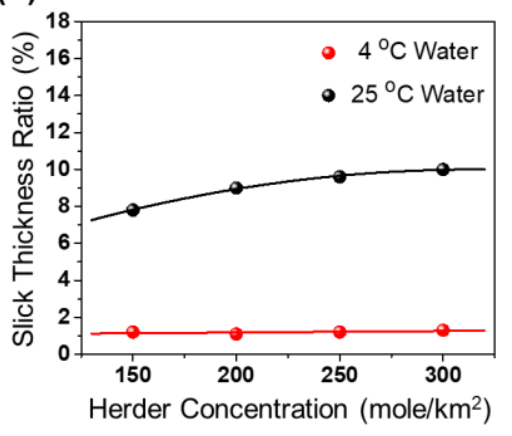

(c)



Fig. 5. PEG-monolaurate herding surfactant efficiency evaluation. Oil-slick thickness ratio changes with the herder surfactant concentration. (a) Comparison of herder PEG-monolaurate and herder Span-20 at $25{ }^{\circ} \mathrm{C}$. (b) Comparison of herder PEG-monolaurate at $4{ }^{\circ} \mathrm{C}$ water and $25{ }^{\circ} \mathrm{C}$ water. (c) Comparison of herder PEG-monolaurate in $3.5 \%$ saline water and pure DI water.

Herein, the natural konjac was studied to explore the its possibility to work as oil herders. Similar to PEG, konjac is a water soluble polymer and has more hydroxyl (-OH) group to functionalize as surfactants (Dave et al., 1998; Nishinari, 2000). Konjac naturally contains of great amounts of natural polysaccharide (Katsuraya et al., 2003; Y.-q. Zhang et al., 2005). Its chemical structure is shown in Fig. 6(a). Konjac is grown mostly in Asian countries, including Japan, Korea, China, and southeast Asia countries. The konjac corm is as shown in Fig. 6(b). Konjac is broadly utilized in the food, nutraceutical, and cosmetics industries. The greatest value of konjac corm flour (as shown in Fig. 6(c)) is its component konjac glucomannan (KGM). Konjac is the only economic crop that can provide KGM in large quantities. Natural polysaccharides have recently garnered interest in the polymeric surfactants area because of their facile production, environmental friendliness, and non-toxic characteristics(Behera and Ray, 2016; Takigami, 2009; Tester and Al-Ghazzewi, 2016).

(a)

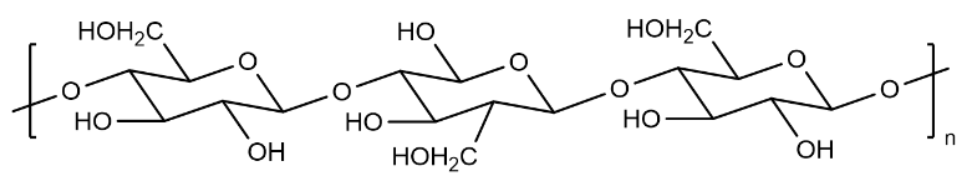

(b)

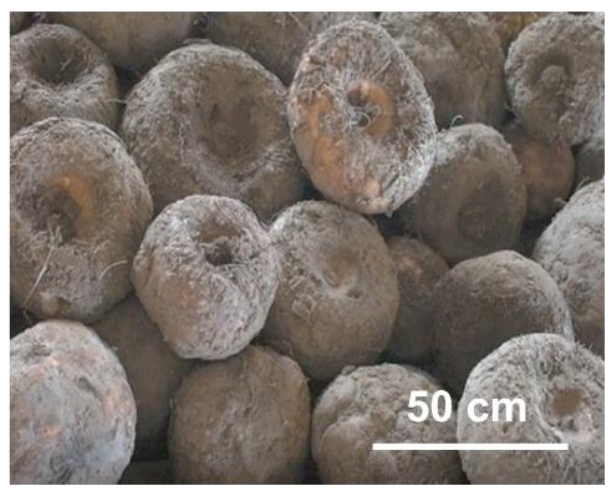

(c)

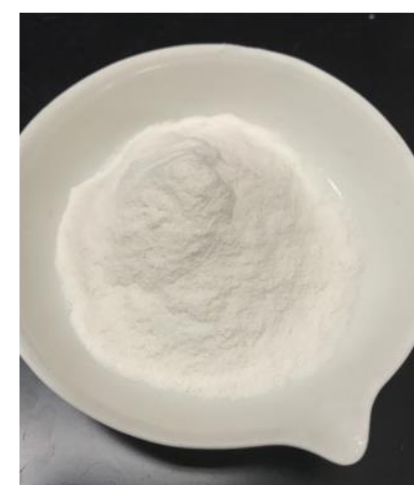


Fig. 6. Konjac glucomannan (KGM). (a) Chemical structure of KGM. (b) Image of konjac corm. (c) Photograph of KGM powder processed from konjac corm.

KGM powder needs to perform the pretreatment before further surface functionalization. The undegraded KGM polymer has large molecular weight and very long hydrophilic backbone which will increase time to form monolayer on water-air surface and further increase the herding time(Luo et al., 2012; H. Zhang et al., 2001). Polymer degradation needs to be taken to shorten the polymer chain length, which could be later testified through molecular weight measurement. Smaller molecular weight suggests shorter polymer backbone chain. The degraded polymer surfactant had shorter chains and required less time for backbone to stretch out to form monolayer for more efficient herding. Furthermore, the degraded surfactant has decreased polymer coil in tendency due to the efficient packing of hydrophobic tails and prevented unnecessary aggregates formation, reducing the invalid polymer aggregate surfactant (Babak and Desbrières, 2004; Henni et al., 2005; Muhd Julkapli et al., 2011).

High energy particle beam like $\gamma$-ray or e-beam was already broadly used for polysaccharides backbone chain scission (Gryczka et al., 2009; Woo and Sandford, 2002; Xu et al., 2007). In our work, the long polymeric chain broke down using the e-beam irradiation. The degradation mechanism of KGM by the chain scission of the polymeric chain is carried out by irradiating the KGM samples with radiation doses of $1.21 \mathrm{kGy}, 5 \mathrm{kGy}, 9 \mathrm{kGy}$ and $16 \mathrm{kGy}$. Gy (Gray) is an SI-derived unit of ionizing radiation and $1 \mathrm{kGy}=1000 \mathrm{~J} / \mathrm{Kg}$.

The functionalized konjac glucomannan (MKGM) synthesis route was as shown in Fig. 7. The detailed synthesis procedure was explained in section 3.2.2. Two chemical functionalized steps were performed. After octadecyl isocyanate (ODI) treatment in step 1, and 1,3- propane sultone in step 2 were chemically grafted, the MKGM surfactant was achieved for use.

Step 1

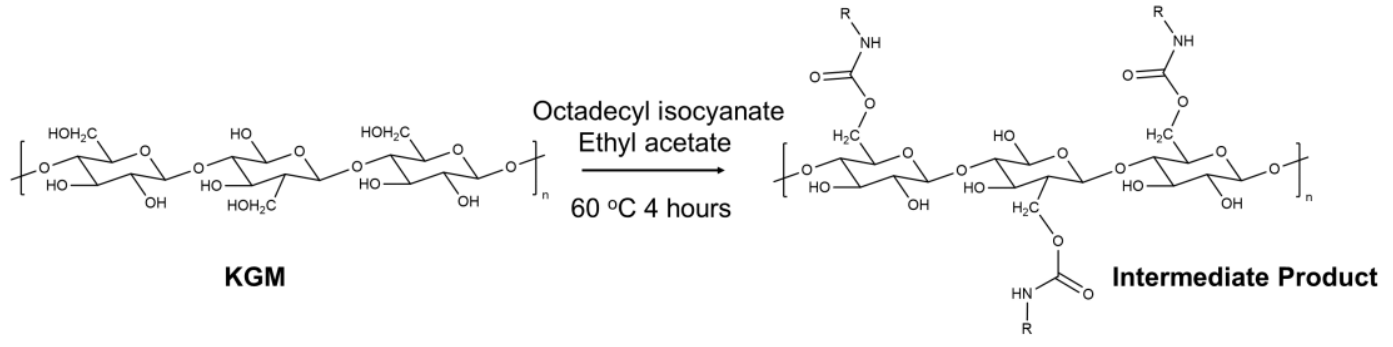

Step 2
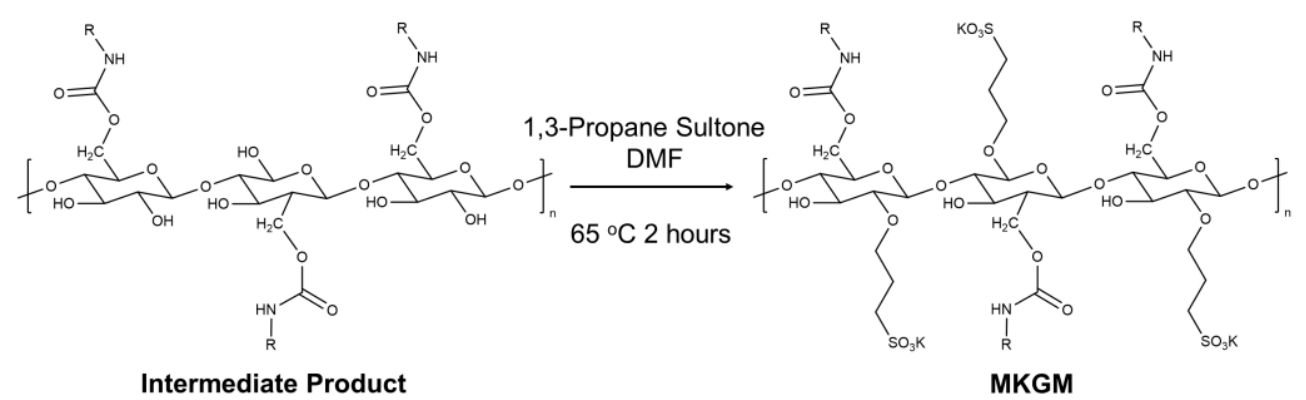

Fig. 7. Functionalized KGM synthesis route. 
Fourier transform infrared spectroscopy (FTIR) and gel permeation chromatography (GPC) were investigated for proving surface functionalization of MKGM and the e-beam radiation effect (shown in Fig. 8). Pristine KGM and MKGM was carried out through FTIR. From Fig. 8(a), the peaks for MKGM at $1390 \mathrm{~cm}^{-1}$ and at $1650 \mathrm{~cm}^{-1}$ represented $\mathrm{S}=\mathrm{O}$ and $\mathrm{C}=\mathrm{O}$ groups, while KGM didn't show peak in the same wavelength. This variance indicated the chemical reaction of synthesis, ODI successfully grafted to KGM in step 1 and 1,3-Propane Sultone in step 2 from Fig. 7. Fig. 8(c) represented GPC molecular weight result related to e-beam radiation. It was clear that the molecular weight of KGM gradually decreased after exposure to e-beam radiation. The molecular weight decreased to $290,000 \mathrm{~g} / \mathrm{mol}$ at $16 \mathrm{kGy}$ radiation compared with initial 1,000,000 $\mathrm{g} / \mathrm{mol}$. As discussed above, the lower-molecular-weight MKGM exhibited better herding surfactant efficiency. Further investigation was undertaken to examine the internal physical structure of pristine KGM and MKGM through scanning electron microscope (SEM). Fig. 8(b) and Fig. 8(d) revealed that KGM and MKGM exhibited an irregular shape and no clear difference between them was observed, proving that the e-beam radiation and surface functionalization did not break the macrostructure of konjac powder.

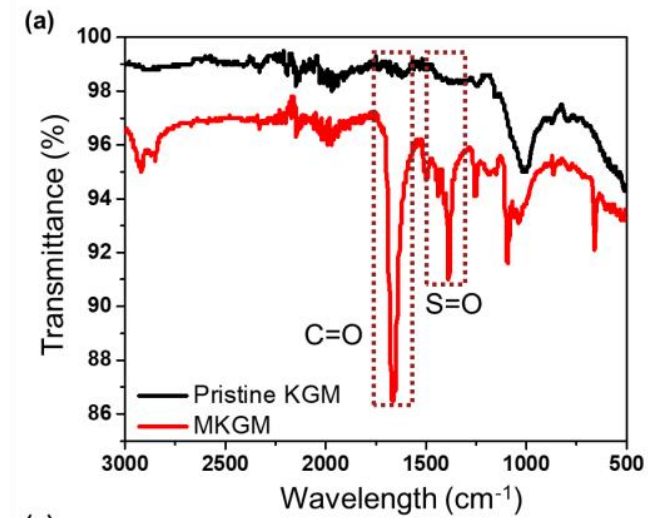

(b)
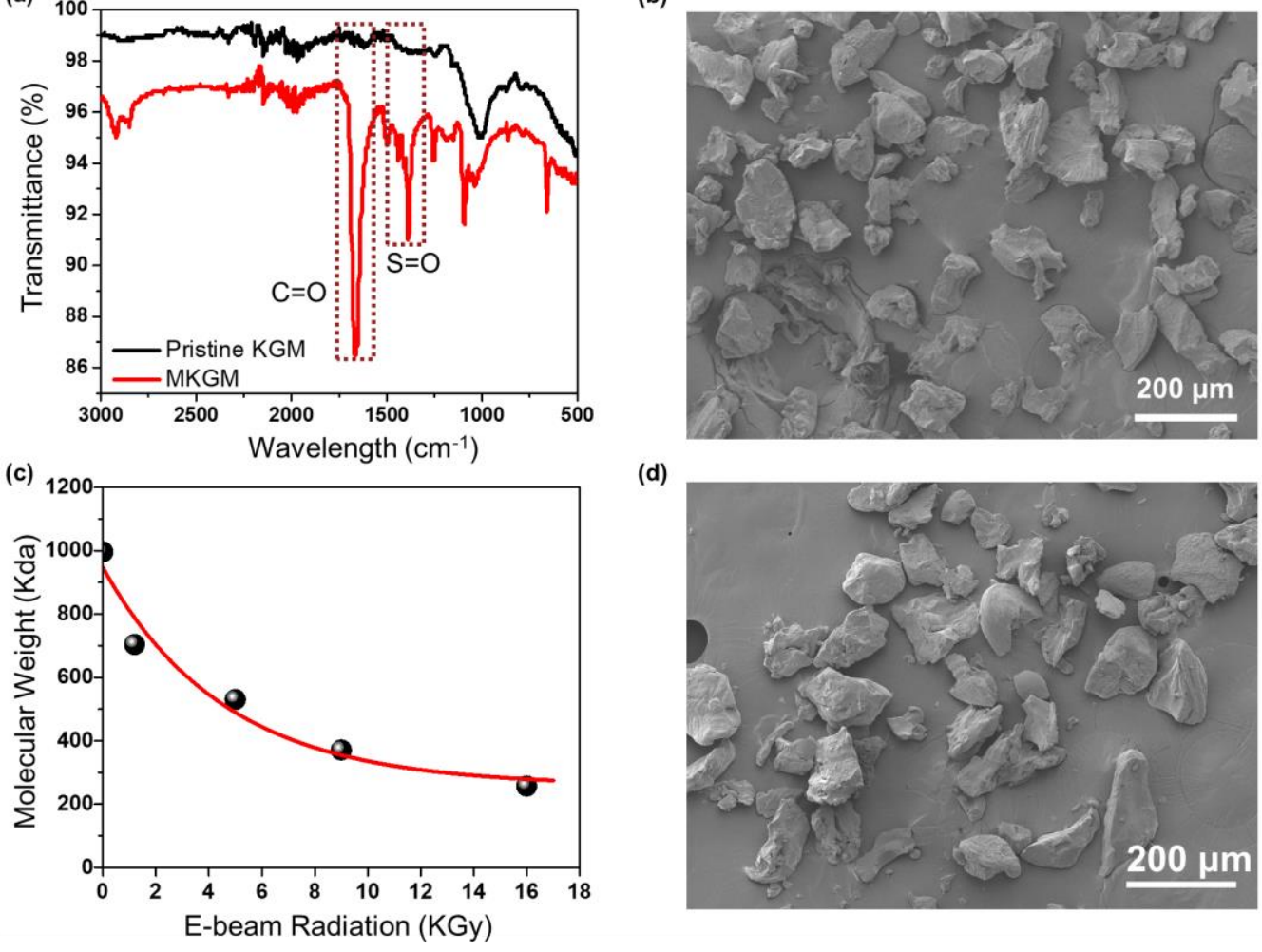

(d)

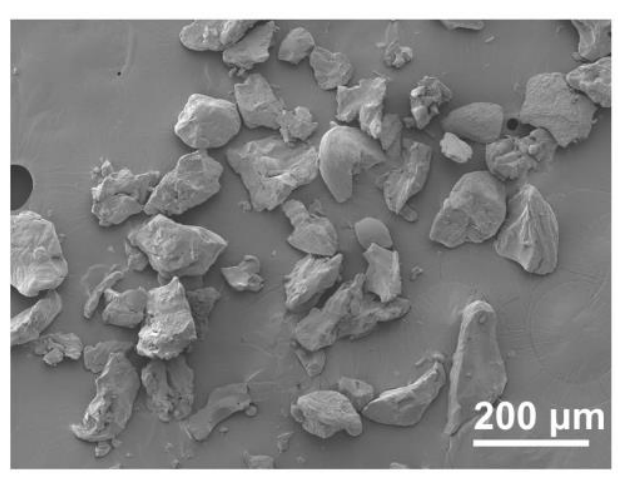

Fig. 8. Chemical characterization of KGM. (a) FTIR spectra of pristine KGM and MKGM. (b) SEM image of pristine KGM powder. (c) Molecular weight of MKGM under various e-beam radiation dosage. (d) SEM image of MKGM at $16 \mathrm{kGy}$ radiation.

The efficacy of MKGM herder in different solvent delivery agents (water and toluene), were investigated. The MKGM tested in this case had been subjected to a $9 \mathrm{kGy}$ radiation dosage. 
Fig. 9 showed oil herding through MKGM at $25{ }^{\circ} \mathrm{C}$ in water (Fig. 9(a) and Fig. 9(b)) and toluene (Fig. 9(c) and Fig. 9(d)) in the crystallization dish. Software ImageJ was used to analyze the images of the oil slick area in different times.

From Fig. 9(a), water was used for the solvent delivery agent. $0.4 \mathrm{ml}$ dodecane (dyed red), simulating an oil spill, was applied to the water surface. Once the oil layer stabilized, $0.25 \mathrm{wt} \%$ herder in water $(0.2 \mathrm{ml})$ was spread to the edge of oil layer through a pipette. After 30 minutes of oil herding process, the oil area reached equilibrium and herding process was complete (Fig. 9(b)). The herding process was effective but slow. The solvent polarity was assumed to be a factor in the efficiency of the herding process.

It has been reported that toluene could be used as the solvent delivery agent (Gupta et al., 2015). From Fig. 9(c), the nonpolar solvent toluene replaced water in the crystallization dish. Similarly, $0.4 \mathrm{ml}$ dodecane (dyed red) simulating an oil spill was applied on the surface and allowed to reach equilibrium, then $0.25 \mathrm{wt} \%$ herder in toluene $(0.2 \mathrm{ml})$ was spread to the edge of oil layer to start the herding process. Time to equilibrium and the herding time decreased to 8 minutes. Water needed to take 2.75 times longer than toluene and toluene proved to be the better delivery agent. The herding improvement might result from the better distribution of the MKGM. Considering the lower density of toluene and its nonpolar characteristics, the MKGM macromolecules dispersed with toluene would form a thin layer in the air-water interface instead of diffusing into water. This behavior would reduce the time for the macromolecules to align the air-water interface and thus reduce the oil herding process.

(a)

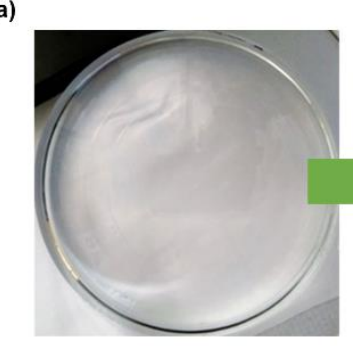

$\mathbf{t}=\mathbf{0} \mathrm{min}$

(c)

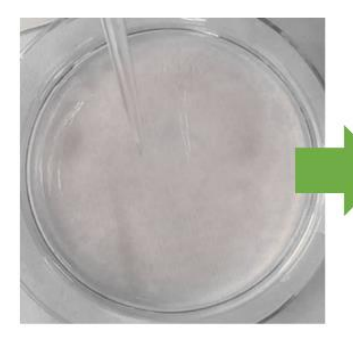

$\mathbf{t}=\mathbf{0} \mathrm{min}$

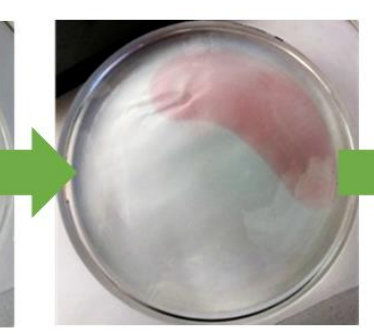

$\mathrm{t}=15 \mathrm{~min}$



$\mathrm{t}=\mathbf{2} \mathrm{min}$

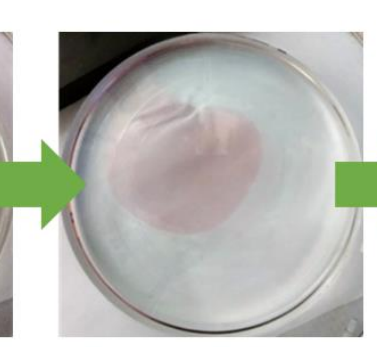

$\mathrm{t}=\mathbf{3 0} \mathrm{min}$
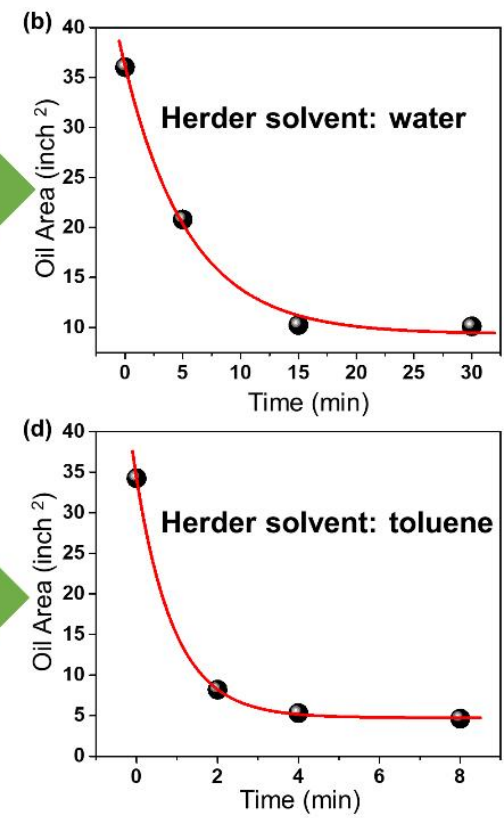

Fig. 9. Oil herding with MKGM surfactant. (a) Photographs of herding process with MKGM herder dispersed in water. (b) Evaluation of herding oil slick area versus time (min) with MKGM herder dispersed in water. (c) Photographs of herding process through MKGM herder dispersed in 
toluene. (d) Evaluation of herding oil slick area versus time (min) with MKGM herder dispersed in toluene.

The e-beam radiation dosage of MKGM then was evaluated to affect herding efficiency in low temperature areas. Sea water was cooled to and maintained at $1{ }^{\circ} \mathrm{C}$ and the circulating bath flow was set to the bottom of crystallizing dish for maintaining the low temperature environment. Fig. 10(a) and Fig. 10(b) demonstrated the herding process with MKGM receiving e-beam radiation dosages of $1.21 \mathrm{kGy}$ and $16 \mathrm{kGy}$. Software ImageJ was used to evaluate the oil slick areas in different times. The oil slick data was as recorded in Fig. 10(c). The oil slick area first decreased and finally stabilized. The herding process was complete at 14 minutes (1.21 kGy) and 10 minutes $(\mathrm{kGy})$. Then all different e-beam radiation dosage of MKMG herding were performed and the herding time was measured as shown in Fig. 10(d). The herding times of $14.5 \mathrm{~min}, 12 \mathrm{~min}, 10$ $\mathrm{min}$, and $6 \mathrm{~min}$, showed a linear relation with radiation dosage. The results further demonstrated that the lower-molecular-weight MKGM (achieved from various dosing e-beam radiation) exhibited better herding surfactant efficiency.

(a)

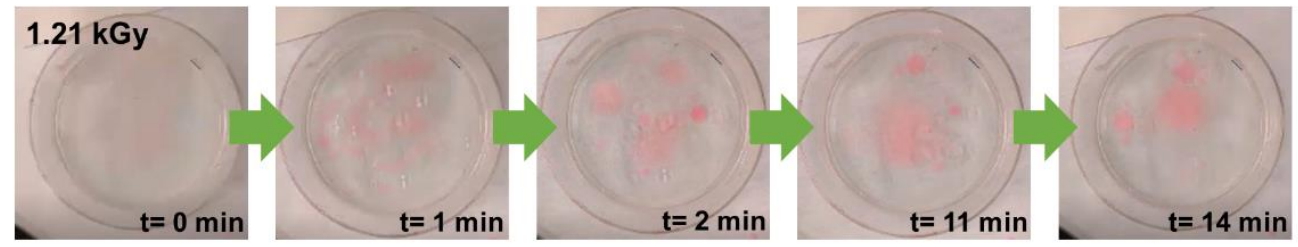

(b)



(c)

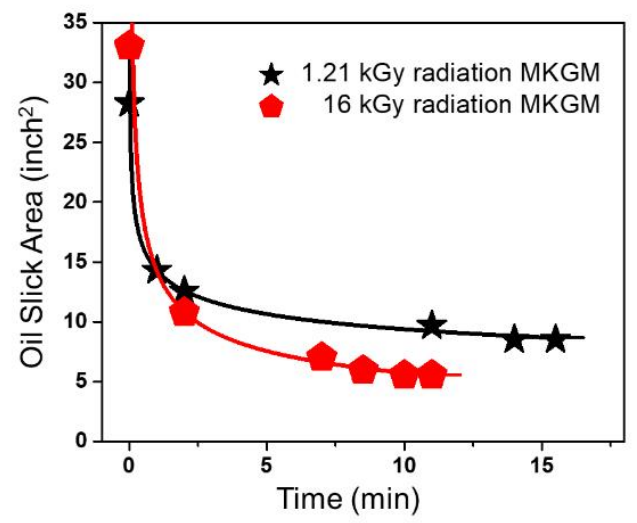

(d)

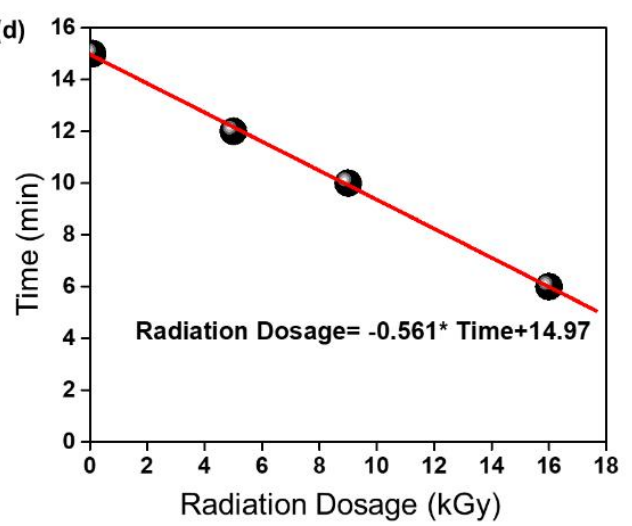

Fig. 10. Oil herding with degraded MKGM with various radiation dosage in low temperature water $\left(1^{\circ} \mathrm{C}\right.$ water) The toluene ratio $0.005(\mathrm{wt} / \mathrm{vol})$ and $0.4 \mathrm{ml}$ of mixture is applied on the $0.4 \mathrm{ml}$ dodecane (oil layer) $1{ }^{\circ} \mathrm{C}$ water. (a) $1.21 \mathrm{kGy}$ (b) $16 \mathrm{kGy}$ (c)Time versus radiation (d) Evaluation of herding oil slick area versus time (min) with MKGM herder dispersed in toluene. 
Krafft temperature and solubility behavior of the ionic surfactant SDS and the non-ionic surfactant MKGM were detailed discussed in Fig. 11. Fig. 11(a) and Fig. 11(c) were the data of SDS and MKGM conductivity versus temperature, and Fig. 11(b) and Fig. 11(d) drew the plot of ionic and non-ionic surfactant molecular arrangement. The conductivity measurement was proven to be able to identify the Krafft temperature. Detailed measurement was discussed in section 3.2.3. As discussed above, Krafft temperature is the minimum temperature for surfactant to form micelles. There is an abrupt large solubility increase above the Krafft temperature. Surfactant working temperature should be higher than Krafft temperature for surfactant functioning.

From Fig. 11(a), there was a clear increase in conductivity with temperature. There were 3 parts for the data set. Within the first part $\left(13{ }^{\circ} \mathrm{C}\right.$ to $\left.14.4{ }^{\circ} \mathrm{C}\right)$, the conductivity increase in conductivity was slow. In the second part starting from $14.6^{\circ} \mathrm{C}$, there was a sudden large increase in conductivity, which demonstrating that the Krafft temperature and the monomer solubility achieved to critical micelle concentration (CMC). Starting from the second part, the micelles formed while monomers began to decrystallize. In the third part, the conductivity increment speed slowed down and micelles were still forming. Correspondingly, schematic illustration of ionic surfactant molecular alignment with the temperature, was explained in Fig. 11(b). Fig. 11(b1) showed the crystallized monomers of the ionic surfactants below the Krafft temperature. Monomers crystallized and have no herding surfactant shape and effect. Fig. 11(b2) represented the formation of micelles when the Krafft temperature was crossed and the micelles increase conductivity of the solution. In Fig. 11(b3), there was continuing formation of micelles. From the figure, the ionic surfactant crystallized and had no herding surfactant functionality below Krafft temperature. The ionic surfactant was only working while the atmosphere temperature was above Krafft temperature. This restriction also largely limited the surfactant usage rate.

Different with ionic surfactants, the non-ionic surfactant MKGM exhibited distinct conductivity tendencies versus temperature. In Fig. 11(c), there was a steady decrease in the conductivity of the solution with temperature increment. Unlike SDS, MKGM did not show any abrupt increase in conductivity and did not appear to have a Krafft temperature. The molecular alignment of non-ionic was performed in Fig. 11(d). The hydrophilic polymer chain was stretching in low temperature and will started to coil-in in high temperature to some extent. (Fig. 11(d1)-Fig. 11(d3)). The molecular alignment did not affect the surfactant functioning well. The absence of Krafft temperature for non-ionic surfactant is a great advantage in low temperature $\left(0{ }^{\circ} \mathrm{C}\right)$ oil spill treatment environment, while ionic surfactant would crystallize to solid and lost herding efficiency in that temperature range. 
(a)

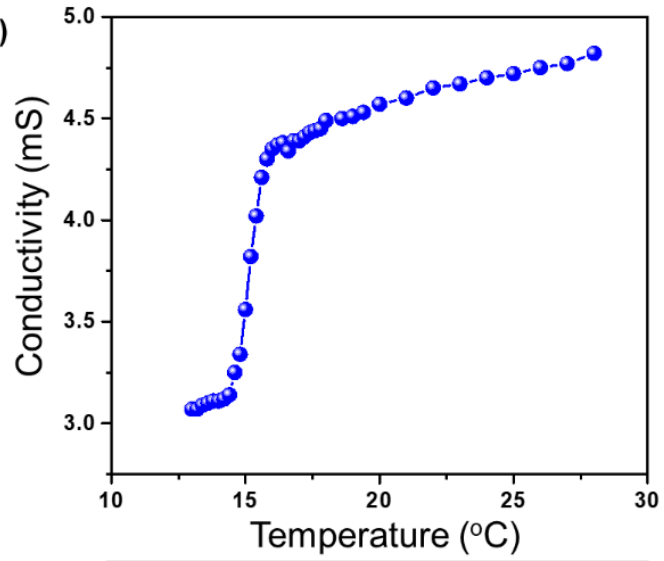

(c)

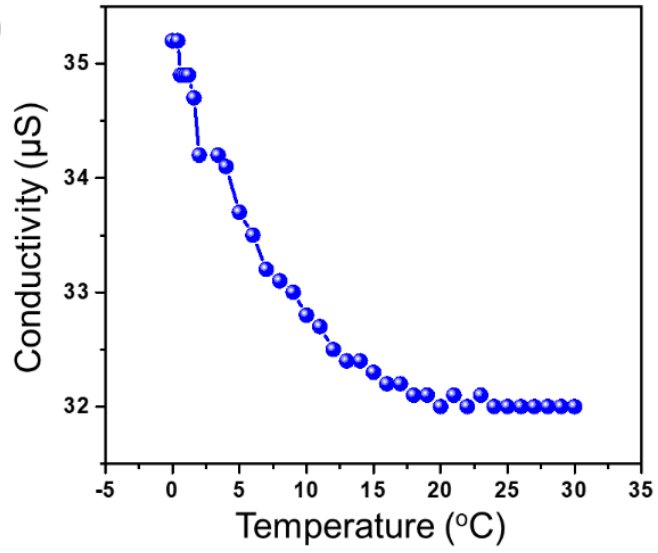

(b)

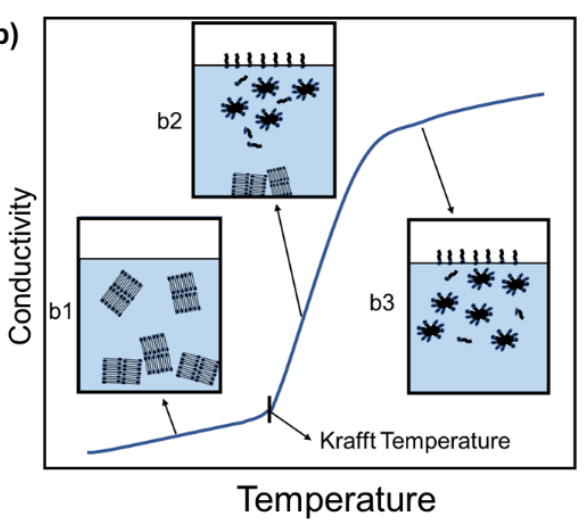

(d)

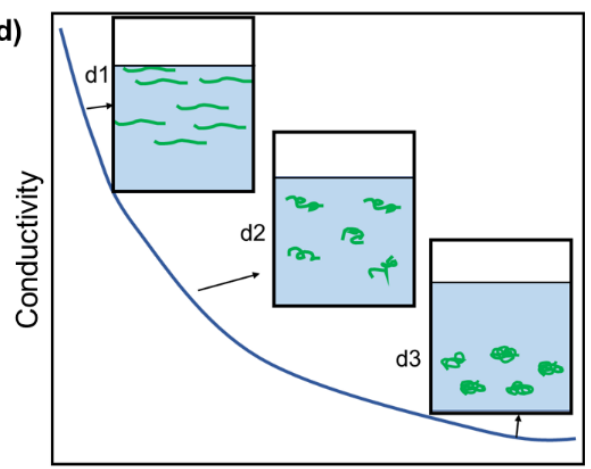

Temperature

Fig. 11. Comparison of mechanism of ionic and non-ionic herding surfactant efficiency. (a) Ionic surfactant SDS: graph of conductivity of SDS solution in water versus temperature. (b) Schematic illustration of relation with ionic surfactant conductivity versus temperature and resulting molecular alignment. (c) Non-ionic surfactant KGM: graph of conductivity of MKGM in water versus temperature. (d) Schematic illustration of relation with non-ionic surfactants conductivity versus temperature and resulting molecular alignment.

In addition, commercialization potential for the MKGM herder was evaluated. The prices of commercial surfactant PEG-400, PEG-1500 and PEG-Sorbitan derivative are $\$ 39.00 / \mathrm{kg}$, $\$ 83.50 / \mathrm{kg}$ and $\$ 64.22 / \mathrm{kg}$ from Sigma-Aldrich company. In comparison, the functionalized KGM was calculated to be $\$ 29.00 / \mathrm{kg}$, which proved to be a promising surfactant candidate for oil spill mitigation in industry.

Finally, a simple biocompatibility test was performed for the MKGM herder, as shown in Fig. 12. Edible black beans, red beans, and pinto beans were purchased from local supermarket. 12 black beans, 12 red beans, and 9 pinto beans were randomly chosen and set aside in lab atmosphere for 7 days (Fig. 12 (a)-(c)). All beans did not sprout and kept their original shape. We then separated beans into three plastic petri dishes, into which four black beans, four red beans and three pinto beans each were placed. Three water environments were simulated, and beans were immersed with reference sea water, $0.25 \mathrm{wt} \%$ pristine KGM in sea water, and $0.25 \mathrm{wt} \% \mathrm{MKGM}$ 
in sea water for 7 days (Fig. 12(d)-(f)). All beans sprouted in a normal speed. The KGM and Surface modification of KGM in sea water did not affect the growth of the beans, which also proved the biocompatibility of the herder.
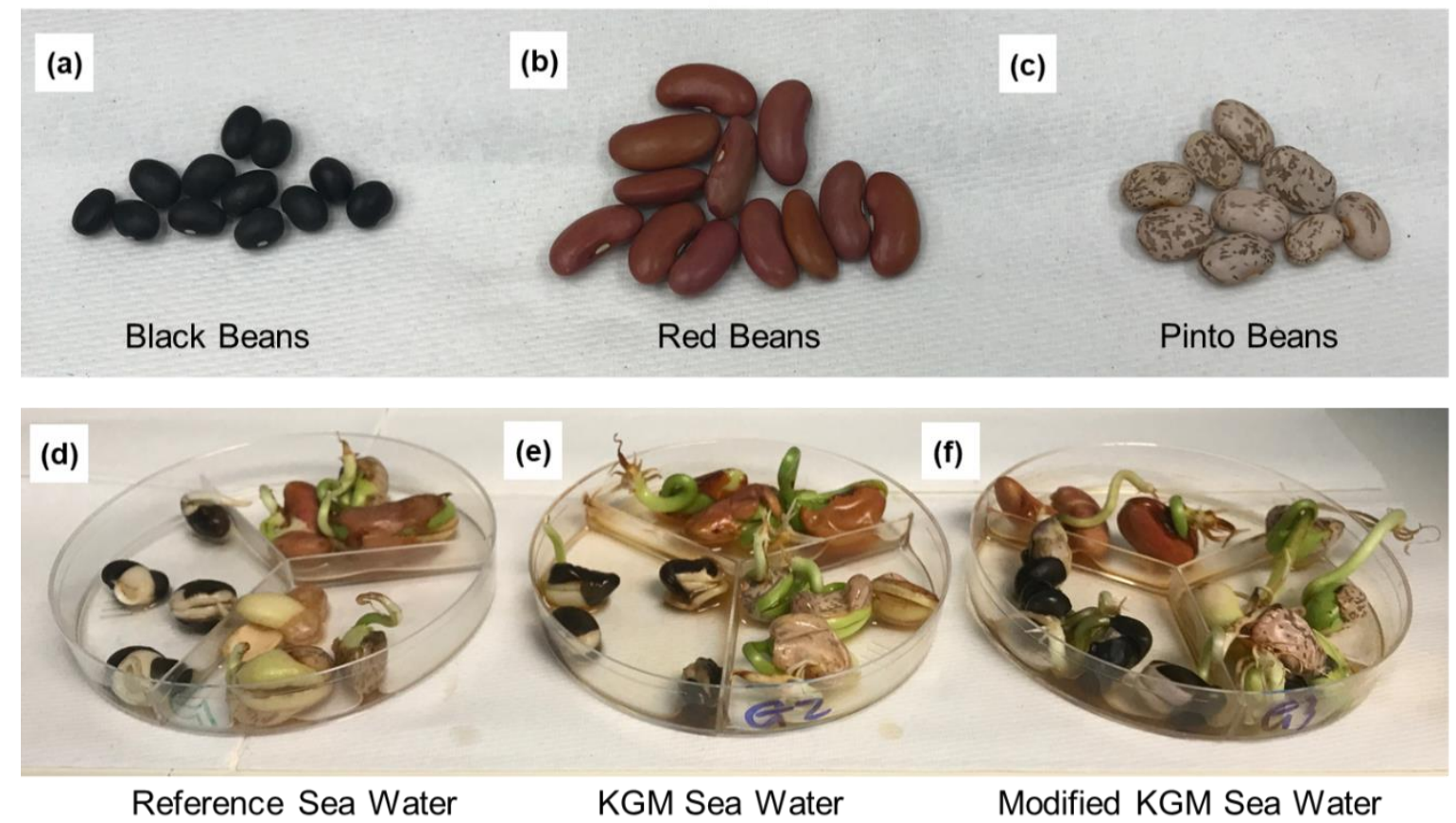

Fig. 12. Biocompatible test for MKGM herding surfactant. Photographic images of edible beans, (a) Black beans, (b) Red beans and (c) Pinto beans. Photographic images of successful bean sprouting in various water environment. (d) Beans in reference sea water, (e) Beans in KGM sea water and (f) Beans in MKGM sea water.

\section{Materials and methodologies}

\subsection{Chemicals and materials}

Pristine KGM powder (Ticagel® Konjac High Viscosity) was achieved from TIC Gums company. Octadecyl isocyanate, ethyl acetate, 1,3-propane sultone, potassium carbonate and N, N - dimethyl formamide were purchased from Sigma-Aldrich.

Black beans, red beans and pinto beans were purchased from a local HEB supermarket.

\subsection{Experimental Methodologies}

\subsubsection{Electron beam radiation of KGM powder for degradation}

Four laboratory zipper reclosable polyethylene (PE) bags were prepared, and into each was packaged five grams of pristine KGM powders. The dimension of the PE bag was $7.5 \mathrm{~cm} \times 14 \mathrm{~cm}$. The PE bags were separately placed on a conveyor belt and transferred into the e-beam processing chamber. The samples were irradiated at dosages of $1.21 \mathrm{kGy}, 5 \mathrm{kGy}, 9 \mathrm{kGy}$ and $16 \mathrm{kGy}$. Gy (Gray) 
is an SI-derived unit of ionizing radiation. $1 \mathrm{~Gy}$ is equal to $1 \mathrm{~J} / \mathrm{Kg}$, representing the absorption of 1 joule of radiation per kilogram.

\subsubsection{Surface functionalization of degraded KGM}

The synthesis route of the herding surfactant was performed in a two-step chemical process as shown in the Fig. 8. The first step was hydrophobic surface functionalization of the KGM. The KGM was first dried in a vacuum drier for 24 hours to remove residual moisture. An amount of 5 $\mathrm{g}$ of KGM was taken in a $250-\mathrm{ml}$ round-bottom flask, and ethyl acetate $(100 \mathrm{ml})$ was added. The mixture was shaken manually for 1 minute and then sonicated for 15 minutes in VWR Model 50T Ultrasonic cleaner to get a homogenous mixture. The hydrophobization of KGM was carried out using octadecyl isocyanate (ODI). The hydrophobic tail was grafted to the KGM structure. An amount of 1 gram of ODI was added to the round-bottom flask and then sonicated repeatedly for 15 minutes. The chemical grafting took place under continuous stirring for 4 hours at $60{ }^{\circ} \mathrm{C}$. The mixture was then centrifuged in a CL 2 Centrifuge at $3900 \mathrm{rpm}$ for 3 minutes to separate the solvent from the reacted mixture. The residue mixture was again washed in ethyl acetate and re-centrifuged at 3,900 rpm for 5 minutes. The excess ethyl acetate was drained out and the residual mixture was dried overnight in the vacuum pump in preparation for step 2. Step 2 consisted of attaching charges to the polymeric chain. In the second step, a $1 \mathrm{~g}$ sample was put in a 250-ml round-bottom flask. Added to the flask were $0.5 \mathrm{ml} \mathrm{1,3-propane} \mathrm{sultone,} 0.15 \mathrm{~g}$ potassium carbonate, and $20 \mathrm{ml}$ solvent $\mathrm{N}, \mathrm{N}$ - dimethyl formamide, and the mixture was continuously stirred at $70{ }^{\circ} \mathrm{C}$ for 1.5 hours. The mixture was centrifuged at $3900 \mathrm{rpm}$ for 4 minutes to separate the solvent. The residue was washed again in acetone and re-centrifuged at $3900 \mathrm{rpm}$ three times for 3 minutes each time. The acetone was drained out and the residual mixture was dried in the vacuum pump overnight to form the MKGM.

\subsubsection{Surfactant conductivity measurement}

SDS (ionic surfactant): SDS in DI water solution (0.1 mol/l) was prepared in a $200 \mathrm{ml}$ glass beaker. The solution was stored in refrigerator at $5{ }^{\circ} \mathrm{C}$ for 24 hours. The SDS surfactant has crystallized below the $5{ }^{\circ} \mathrm{C}$ atmosphere. The glass beaker was taken out of the refrigerator and placed on a hot plate stirrer. The conductivity meter probe was immersed into the solution. The dual measuring mode of conductivity meter could measure both the conductivity and the temperature. The solution was slightly heated to remain $0.2^{\circ} \mathrm{C} / \mathrm{min}$ increase. The measured conductivity and temperature data were drawn in Fig. 11(a).

MKGM (non-ionic surfactant): $0.25 \mathrm{wt} \%$ of MKGM (16 kGy) in $200 \mathrm{ml}$ water solution was kept overnight under refrigeration to maintain the temperature at $0{ }^{\circ} \mathrm{C}$. The conductivity meter probe immersed into the solution measured both the conductivity and temperature. The solution was slightly heated to achieve $0.2^{\circ} \mathrm{C} / \mathrm{min}$ increment. The conductivity versus temperature plot is shown in Fig. 11(c).

\subsection{Characterization}

The morphologies of pristine and modified konjac particles were imaging at JSM-7500F JEOL field-emission scanning electron microscope (FE-SEM). The molecular weight measurement was performed at TOSOH ambient temperature gel permeation chromatography system (GPC). The chemical structure of konjac particles were tested through Fourier-transform infrared spectroscopy (FTIR). All photographs were taken through Supereyes B007 USB digital microscope portable 
camera and SONY Alpha a600 camera. The temperature tests in this work were measured with thermometer Omega hh11b. The conductivity was tested with CON 6 hand-held conductivity meter.

\subsection{ImageJ Software Analysis}

ImageJ was the software for analyzing and calculating the oil slick areas in this work. It is an imaging processing program through Java-based language and could transfer colorful photograph into black \& white photograph for pixels analyzing. Through ImageJ, every oil herding picture was transferred into pixels. The crystallizing dish area was known and transferred to pixels. Then the oil slick occupied black pixels were measured and converted to oil slick areas by the crystallizing dish pixels. Thus, the different herding time oil slick areas were achieved.

\section{Conclusion}

In this work, a novel biocompatible, highly environmental MKGM herding surfactant, was developed for rapid oil spill remediation. The synthesized MKGM surfactant was able to retract oil area efficiently. MKGM's non-ionic surfactant characteristics allows it to function without susceptibility to Krafft temperature, giving MKGM surfactants the unique ability to maintain surfactant function at temperatures approaching $0{ }^{\circ} \mathrm{C}$. The ability to perform unaffected by low temperature is a great advantage compared with traditional ionic surfactant, as most are not able to function under $5{ }^{\circ} \mathrm{C}$. Considering the increasing oil drilling in Arctic areas and inevitable oil spills, it offers a new direction to act as newly efficient oil herders for a wide range water temperature.

\section{Acknowledgements}

This research is partially supported by Mary Kay O'Connor Process Safety Center, Texas A\&M University. We would like to thank National Center for Electron Beam Research for the KGM ebeam radiation. We acknowledge Materials Characterization Facility at Texas A\&M University for performing FE-SEM and FTIR test. We acknowledge Dr. David Truong at Soft Matter Facility at Texas A\&M University for GPC measurement.

\section{References}

Aggarwal, S., Schnabel, W., Buist, I., Garron, J., Bullock, R., Perkins, R., . . . Cooper, D., 2017. Aerial application of herding agents to advance in-situ burning for oil spill response in the Arctic: A pilot study. Cold Regions Science and Technology, 135, 97-104.

Babak, V. G., \& Desbrières, J., 2004. Dynamic surface tension of hydrophobically modified chitosans. Mendeleev Communications, 14(2), 66-69.

Baffes, J., 2007. Oil spills on other commodities. Resources Policy, 32(3), 126-134. doi:https://doi.org/10.1016/j.resourpol.2007.08.004

Bakshi, M. S., \& Singh, K., 2005. Synergistic interactions in the mixed micelles of cationic gemini with zwitterionic surfactants: fluorescence and Krafft temperature studies. Journal of colloid and interface science, 287(1), 288-297.

Behera, S. S., \& Ray, R. C., 2016. Konjac glucomannan, a promising polysaccharide of Amorphophallus konjac K. Koch in health care. International journal of biological macromolecules, 92, 942-956. 
Blumer, M., Sanders, H. L., Grassle, J. F., \& Hampson, G. R., 1971. An ocean of oil: a small oil spill. Environment: Science and Policy for Sustainable Development, 13(2), 2-12.

Brown, G. G., Graves, G. W., \& Ronen, D., 1987. Scheduling ocean transportation of crude oil. Management Science, 33(3), 335-346.

Dave, V., Sheth, M., McCarthy, S. P., Ratto, J. A., \& Kaplan, D. L., 1998. Liquid crystalline, rheological and thermal properties of konjac glucomannan. Polymer, 39(5), 1139-1148.

Goldberg, V. P., 1994. Recovery for Economic Loss following the Exxon" Valdez" Oil Spill. The Journal of Legal Studies, 23(1), 1-39.

Gryczka, U., Dondi, D., Chmielewski, A. G., Migdal, W., Buttafava, A., \& Faucitano, A., 2009. The mechanism of chitosan degradation by gamma and e-beam irradiation. Radiation Physics and Chemistry, 78(7-8), 543-548.

Gupta, D., Sarker, B., Thadikaran, K., John, V., Maldarelli, C., \& John, G., 2015. Sacrificial amphiphiles: Eco-friendly chemical herders as oil spill mitigation chemicals. Science advances, 1(5), e1400265.

Henni, W., Deyme, M., Stchakovsky, M., LeCerf, D., Picton, L., \& Rosilio, V., 2005. Aggregation of hydrophobically modified polysaccharides in solution and at the airwater interface. Journal of colloid and interface science, 281(2), 316-324.

Iakovou, E., Ip, C. M., Douligeris, C., \& Korde, A., 1997. Optimal location and capacity of emergency cleanup equipment for oil spill response. European Journal of Operational Research, 96(1), 72-80.

Imai, T., Tsuchiya, S., Morita, K., \& Fujimori, T., 1994. Surface tension-dependent surfactant toxicity on the green peach aphid, Myzus persicae (Sulzer)(Hemiptera: Aphididae). Applied Entomology and Zoology, 29(3), 389-393.

Inácio, Â. S., Costa, G. N., Domingues, N. S., Santos, M. S., Moreno, A. J. M., Vaz, W. L. C., \& Vieira, O. V., 2013. Mitochondrial dysfunction is the focus of quaternary ammonium surfactant toxicity to mammalian epithelial cells. Antimicrobial agents and chemotherapy, 57(6), 2631-2639.

Jesus, C. D. (2016). Thousands Of "Small” Oil Spills Are Destroying the Gulf of Mexico. Retrieved from https://futurism.com/thousands-of-small-oil-spills-are-destroying-thegulf-of-mexico

Katsuraya, K., Okuyama, K., Hatanaka, K., Oshima, R., Sato, T., \& Matsuzaki, K., 2003. Constitution of konjac glucomannan: chemical analysis and 13C NMR spectroscopy. Carbohydrate polymers, 53(2), 183-189.

Kaushik, M. (2019). 11 Major Oil Spills Of The Maritime World. Retrieved from https://www.marineinsight.com/environment/11-major-oil-spills-of-the-maritime-world/

Komoto, I., \& Kobayashi, S., 2004. Lewis acid catalysis in supercritical carbon dioxide. Use of poly (ethylene glycol) derivatives and perfluoroalkylbenzenes as surfactant molecules which enable efficient catalysis in ScCO2. The Journal of organic chemistry, 69(3), 680688.

Luo, X., Yao, X., Zhang, C., Lin, X., \& Han, B., 2012. Preparation of mid-to-high molecular weight konjac glucomannan (MHKGM) using controllable enzyme-catalyzed degradation and investigation of MHKGM properties. Journal of Polymer Research, 19(4). doi:10.1007/s10965-012-9849-x

Muhd Julkapli, N., Akil, H. M., \& Ahmad, Z., 2011. Preparation, properties and applications of chitosan-based biocomposites/blend materials: a review. Composite Interfaces, 18(6), 449-507. 
Nishinari, K. 2000. Konjac glucomannan. In G. Doxastakis \& V. Kiosseoglou (Eds.), Developments in Food Science (Vol. 41, pp. 309-330): Elsevier.

Paine, R. T., Ruesink, J. L., Sun, A., Soulanille, E. L., Wonham, M. J., Harley, C. D. G., . . . Secord, D. L., 1996. Trouble on oiled waters: lessons from the Exxon Valdez oil spill. Annual Review of Ecology and Systematics, 27(1), 197-235.

Peterson, C. H., Rice, S. D., Short, J. W., Esler, D., Bodkin, J. L., Ballachey, B. E., \& Irons, D. B., 2003. Long-term ecosystem response to the Exxon Valdez oil spill. Science, 302(5653), 2082-2086. Retrieved from https://science.sciencemag.org/content/302/5653/2082.long

Rico, I., \& Lattes, A., 1986. Formamide, a water substitute. 12. Krafft temperature and micelle formation of ionic surfactants in formamide. The Journal of Physical Chemistry, 90(22), $5870-5872$.

Silliman, B. R., van de Koppel, J., McCoy, M. W., Diller, J., Kasozi, G. N., Earl, K., .. . Zimmerman, A. R., 2012. Degradation and resilience in Louisiana salt marshes after the BP-Deepwater Horizon oil spill. Proceedings of the National Academy of Sciences, 109(28), 11234-11239.

Takigami, S. 2009. 32 - Konjac mannan. In G. O. Phillips \& P. A. Williams (Eds.), Handbook of Hydrocolloids (Second Edition) (pp. 889-901): Woodhead Publishing.

Tester, R. F., \& Al-Ghazzewi, F. H., 2016. Beneficial health characteristics of native and hydrolysed konjac (Amorphophallus konjac) glucomannan. Journal of the Science of Food and Agriculture, 96(10), 3283-3291.

Urquhart, R. D., 1986. Heavy Oil Transportation - Present And Future. Journal of Canadian Petroleum Technology, 25(02), 5. doi:10.2118/86-02-05

Vargaftik, N. B., Volkov, B. N., \& Voljak, L. D., 1983. International tables of the surface tension of water. Journal of Physical and Chemical Reference Data, 12(3), 817-820.

Venkataraman, P., Tang, J., Frenkel, E., McPherson, G. L., He, J., Raghavan, S. R., . . John, V. T., 2013. Attachment of a hydrophobically modified biopolymer at the oil-water interface in the treatment of oil spills. ACS applied materials \& interfaces, 5(9), 35723580.

Winger, M., De Vries, A. H., \& Van Gunsteren, W. F., 2009. Force-field dependence of the conformational properties of $\alpha, \omega$-dimethoxypolyethylene glycol. Molecular Physics, 107(13), 1313-1321.

Woo, L., \& Sandford, C. L., 2002. Comparison of electron beam irradiation with gamma processing for medical packaging materials. Radiation Physics and Chemistry, 63(3-6), 845-850.

Xu, Z., Sun, Y., Yang, Y., Ding, J., \& Pang, J., 2007. Effect of $\gamma$-irradiation on some physiochemical properties of konjac glucomannan. Carbohydrate polymers, 70(4), 444450.

Zhang, H., Yoshimura, M., Nishinari, K., Williams, M. A. K., Foster, T. J., \& Norton, I. T., 2001. Gelation behaviour of konjac glucomannan with different molecular weights. Biopolymers: Original Research on Biomolecules, 59(1), 38-50.

Zhang, Y.-q., Xie, B.-j., \& Gan, X., 2005. Advance in the applications of konjac glucomannan and its derivatives. Carbohydrate polymers, 60(1), 27-31. 